\title{
Complications of non-continent cutaneous urinary diversion in adults with spinal cord injury: a retrospective study
}

\author{
Cyrille Guillot-Tantay $\mathbb{1}^{1} \cdot$ Emmanuel Chartier-Kastler $\mathbb{1}^{1} \cdot$ Marie-Aimée Perrouin-Verbe $^{1} \cdot$ Pierre Denys $^{2}$. \\ Priscilla Léon ${ }^{1}$ • Véronique Phé ${ }^{1}$
}

Received: 12 September 2017 / Revised: 8 February 2018 / Accepted: 12 February 2018 / Published online: 7 March 2018

(C) International Spinal Cord Society 2018

\begin{abstract}
Study design Retrospective cohort study.

Objectives To report the long-term complications of non-continent cutaneous urinary diversion (NCCUD) in adult patients with spinal cord injury (SCI).

Setting Hospital in Paris, France.

Methods A retrospective single center study included all adult patients with SCI who underwent an ileal conduit between 1997 and 2014. Early complications were reported according to Clavien-Dindo classification. Long-term complications and reoperation rates were recorded, as well as stoma management and autonomy improvement related to urinary function.

Results One hundred and two patients were included. The surgical indications included failure of intermittent catheterization $(n=43)$, urethral fistulae due to skin ulcers $(n=50)$, renal failure $(n=8)$, recurrent urinary tract infections $(n=9)$, lithiasis $(n=3)$, and bladder tumors $(n=2)$. There were 67 early postoperative complications for 44 patients $(43 \%)$ leading to an additional surgery in 15 cases: 30 grade I-II, 30 grade III, 6 grade IV, and 1 grade V. A total of 37 late complications were reported for 36 patients (35\%): 17 ureteral anastomosis stenosis, 3 stoma hernia, 3 pyocystis (3/15 patients), 7 pyelonephritis, 2 renal failures, 2 ureteral lithiasis, 1 uterine prolapse, 1 incisional hernia, and 1 tumor recurrence. Renal function remained unchanged $(p=0.53)$. Autonomy related to urinary function was improved in $88 \%$ of patients. The correct fitting of the stoma was possible for $81 \%$ of the patients.

Conclusions Despite a perioperative morbidity rate of $43 \%$ and a late complication rate of $35 \%$, as a last resort procedure, NCCUD is an end-stage solution in patients with SCI to preserve renal function and achieve autonomy.
\end{abstract}

\section{Introduction}

The combination of intermittent self-catheterization (ISC), described initially by Lapides et al. [1] in 1972 with the treatment of neurogenic detrusor overactivity is recommended in neurological patients with spinal cord disease in

Cyrille Guillot-Tantay

c.guillot.tantay@gmail.com

1 Department of Urology, Pitié-Salpêtrière Academic Hospital, Assistance Publique-Hôpitaux de Paris, Pierre and Marie Curie Medical School, Sorbonne Universités, Paris 6 University, Paris, France

2 Department of Physical Medicine and Rehabilitation, Raymond Poincaré Academic Hospital, Garches, Assistance PubliqueHôpitaux de Paris, Paris-Ouest Medical School, Versailles-SaintQuentin en Yvelines University, Montigny le Bretonneux, France order to improve the storage phase, protect the upper urinary tract, and achieve urethral continence $[2,3]$. In case of failure of conservative therapy, non-continent cutaneous urinary diversion (NCCUD) can be offered to these patients in whom ISC cannot be performed due to anatomical barriers, cognitive impairment, or limited dexterity $[4,5]$. Ultimately, NCCUD can be considered in patients who use wheelchairs or are restricted to bed (skin ulcers included), with intractable and untreatable incontinence, in devastated lower urinary tract symptoms, when the upper urinary tract is severely compromised, and in patients who reject other therapy.

The ileal conduit described by Bricker [6] in 1950 is most commonly used and diverts the urine regardless of whether or not a cystectomy is performed [7]. The ileal conduit has been largely reported after pelvic cancer surgery but remains seldom used for the management of neurogenic bladder, since the use of less invasive therapies is preferred 
[8]. The surgical procedure is efficient, however, data are scarce regarding the long-term complications of NCCUD using an ileal conduit in neurological patients [9]. As an end-stage non-reversible surgical procedure, this technique may suffer from having a bad reputation.

Thus, our aim was to report our experience of NCCUD using an ileal conduit, especially among patients with traumatic and non-traumatic spinal cord injury (SCI) regarding outcomes and complications.

\section{Methods}

A retrospective monocentric study included all consecutive adult patients with SCI who underwent an NCCUD between June 1997 and June 2014. The following data were collected: age at surgery, gender, body mass index, underlying neurological disease, duration of the neurological disease, previous urological treatment, pattern of voiding, type of bladder dysfunction, urodynamic parameters, and urinary tract abnormalities assessed by morphologic examination (ultrasound and/or computed tomography scan), cystoscopy, creatinine clearance, and indications for NCCUD. We certify that all applicable institutional and governmental regulations concerning the ethical use of human volunteers were followed during the course of this research.

\section{Surgical technique}

An experienced surgeon and his dedicated team performed the surgeries. All the urinary diversions consisted in an ileal conduit according to the Bricker's technique [6], which were or were not associated with a cystectomy. The technique remained stable throughout the follow-up. Asymptomatic bacteriuria was treated $48 \mathrm{~h}$ prior to surgery and patients received a bowel preparation with polyethylene glycol. By a midline incision, retroperitoneal cystectomy was performed if requested, after both ureters had been identified and prepared for a Wallace anastomosis. The bowel segment used for the ileal conduit was approximately $10 \mathrm{~cm}$ in length and located $20 \mathrm{~cm}$ away from the ileocecal valve. Intestinal anastomosis was performed manually with absorbable suture material or with automatic stitches, according to the surgeon. The uretero-ileal anastomosis was performed according to Wallace's method and stents intubating the ureters were fixed to the new ureteral plate and passed through the ileal lumen [10]. The standard location for the stoma was the right lower quadrant (located and marked the day before surgery). The nasogastric tube was removed when bowel movements resumed. The ureteral stents were successively removed between days 10 and 13 after surgery. An ultrasound was performed $24 \mathrm{~h}$ after stent removal to ensure there was no hydronephrosis.

\section{Follow-up and assessment}

Early complications ( $<30$ days) were reported according to Clavien-Dindo classification and Martin's criteria [11, 12] and classified as followed:

- Grade I: Any deviation from the normal postoperative course without the need for pharmacological treatment or surgical endoscopic and radiological interventions.

- Grade II: Requiring pharmacological treatment with drugs other than those allowed for grade I complications.

- Grade III: Requiring surgical, endoscopic, or radiological intervention.

- Grade IV: Life-threatening complication requiring intensive care.

- Grade V: Death of a patient.

Patients were evaluated at 1,3 , and 6 months after surgery and annually thereafter, through visits in the joint outpatient clinic involving a urologist and a rehabilitation physician. The follow-up assessment included a local clinical examination, an assessment of renal function using the 24-h creatinine clearance test, and a kidney ultrasound. Long-term complications and reoperation rates were recorded, as well as stoma management and autonomy improvement related to urinary function. Autonomy was defined by the capacity of the patient to remain at home without ancillary support for the urological functions. The physician assessed this at each annual visit, asking the patient how he/she used the ileal conduit. The participants were consider autonomous if they did not need anyone to take care of the ileal conduit.

\section{Results}

\section{Participant characteristics}

Overall, 102 consecutive patients with SCI (44 males and 58 females), median age 53.5 years (interquartile range (IQR) 44-63) were included in this cohort study. Table 1 shows the participants' baseline characteristics. Among the participants, 37 (36\%) had a cervical lesion (from $\mathrm{C} 1$ to C8), $53(52 \%)$ had a thoracic lesion (from T1 to T12), and 8 $(8 \%)$ had a lumbar or sacral lesion (from L1 to sacral roots). Among them, $62(61 \%)$ were people with paraplegia and 40 (39\%) were people with tetraplegia, and there were $67 \%$ classified as American Spinal Injury Association Impairment Scale (AIS) A, $12 \%$ AIS B, $17 \%$ AIS C, and 4\% AIS D.

The surgical indications included failure of intermittent catheterization $(n=43)$, urethral fistulae due to skin ulcers 
Table 1 Characteristics of the study population $(n=102)$

Sex

Male

Female

Age at the time of surgery (years) (median, IQR)

Age at the time of beginning of the disease (years) (median, IQR)

Duration of disease at the time of surgery (years) (median, IQR)

Body mass index $\left(\mathrm{kg} / \mathrm{m}^{2}\right)$ (median, IQR)

Level of spinal cord injury

Cervical

Thoracic

Lumbar

Myelitis

Disability

People with paraplegia

People with tetraplegia

Disability situation

Bedbound

Wheelchair dependent

Anorectal disorders

Fecal incontinence

Colostomy

Prior urological treatment

Antimuscarinic drugs

Botulinum toxin A injection

Sphincterotomy procedures

Continence procedures

Koch procedure

Ureterostomy

Cystostomy

Pattern of voiding

Intermittent catheterization

Indwelling catheterization

Reflex voiding

Urodynamic parameters $(n=29)$

Detrusor overactivity

Low bladder compliance

Maximum cystometric capacity $(\mathrm{mL})$ (median, IQR)

Maximum urethral closure pressure $\left(\mathrm{cm} \mathrm{H}_{2} \mathrm{O}\right)$ (median, IQR)

Morphologic abnormalities

Hydronephrosis

Renal atrophy

Vesicoureteral reflux

Indications for NCCUD

Removal indwelling catheter or suprapubic catheter

28
Table 1 (continued)

\begin{tabular}{ll}
\hline Skin ulcers of the perineum & 40 \\
Patients preferences patterns of voiding & 15 \\
Urethrocutaneous fistula & 10 \\
Renal failure or/and renal cavities dilatation & 8 \\
Repeated infections & 9 \\
Lithiasis & 3 \\
Bladder tumors & 2 \\
Creatinine clearance at baseline (mL/min) & $68(50-80)$ \\
(median, IQR) &
\end{tabular}

$37(36 \%)$

$53(52 \%)$

$8(8 \%)$

$4(4 \%)$

$62(61 \%)$

$40(40 \%)$

$2(2 \%)$

$100(98 \%)$

$3(3 \%)$

$6(6 \%)$

$15(15 \%)$

$6(6 \%)$

$14(14 \%)$

$6(6 \%)$

$2(2 \%)$

$1(1 \%)$

$1(1 \%)$

$20(20 \%)$

$64(63 \%)$

$18(18 \%)$

$15(52 \%)$

$4(14 \%)$

$400(270-550)$

$49(28-90)$

$4(4 \%)$

$3(3 \%)$

$4(4 \%)$

$\overline{I Q R}$ interquartile, NCCUD non-continent cutaneous urinary diversion

Table 2 Perioperative data

\begin{tabular}{ll}
\hline Intervention & \\
Cystectomy and NCCUD & $87(85 \%)$ \\
NCCUD alone & $15(15 \%)$ \\
Concomitant procedures $(n=15)$ & \\
$\quad$ Colostomy & $4(27 \%)$ \\
$\quad$ Hysterectomy & $3(20 \%)$ \\
$\quad$ Sacrocolpopexy & $4(27 \%)$ \\
$\quad$ Nephrectomy & $1(7 \%)$ \\
$\quad$ Abdominal wall procedure & $2(13 \%)$ \\
$\quad$ Cholecystectomy & $1(7 \%)$ \\
Duration of the intervention (min) (median, IQR) & $300(240-260)$ \\
Blood loss (mL) (median, IQR) & $800(500-1100)$ \\
Duration of catheterization by ureteral stent (days) & $($ median, IQR) \\
$\quad$ Left & $13(12-14)$ \\
$\quad$ Right & $12(11-14)$ \\
Use of nasogastric tube (days) (median, IQR) & $5(4-6)$ \\
Time to have bowel movement resumed (days) & $6(5-8)$ \\
(median, IQR) & $7(6-8)$ \\
Feeding back (days) (median, IQR) & $20(17-25)$ \\
Postoperative duration of hospitalization (days) \\
(median, IQR)
\end{tabular}

$(n=50)$, renal failure $(n=8)$, recurrent urinary tract infections $(n=9)$, lithiasis $(n=3)$, and bladder tumors $(n$ $=2$ ). Patients who underwent NCCUD were considered unfit for a cutaneous urinary diversion.

Seventy-four participants had a complete follow-up of at least 1 year and the median follow-up was 61.0 months (IQR 26.75-103).

\section{Perioperative data}

The median operative time was $300 \mathrm{~min}$ (IQR 240-360) and the median blood loss was $800 \mathrm{~mL}(500-1100)$. Table 2 summarizes the surgical procedures. A cystectomy was associated to the NCCUD in 87 (85\%) cases. In 15 cases, 
Table 3 Early and late postoperative complications

\begin{tabular}{|c|c|c|c|}
\hline Type & $n$ & Clavien & Surgical management \\
\hline Early (44 patients) & 67 & & 15 \\
\hline Blood transfusion & 22 & $\begin{array}{l}\text { Grade } \\
\text { II }\end{array}$ & \\
\hline $\begin{array}{l}\text { Functional } \\
\text { digestive } \\
\text { occlusion }\end{array}$ & 8 & $\begin{array}{l}\text { Grade } \\
\text { II }\end{array}$ & \\
\hline Pyelonephritis & 13 & $\begin{array}{l}\text { Grade } \\
\text { III }\end{array}$ & $\begin{array}{l}\text { Ureteral stenting or nephrostomy } \\
(n=8)\end{array}$ \\
\hline Respiratory failure & 7 & $\begin{array}{l}\text { Grade } \\
\text { III }\end{array}$ & \\
\hline Renal failure & 2 & $\begin{array}{l}\text { Grade } \\
\text { III }\end{array}$ & \\
\hline Bricker disunion & 2 & $\begin{array}{l}\text { Grade } \\
\text { III }\end{array}$ & Bricker's refection $(n=2)$ \\
\hline Evisceration & 2 & $\begin{array}{l}\text { Grade } \\
\text { III }\end{array}$ & $\begin{array}{l}\text { Abdominal wall reparation }(n= \\
\text { 2) }\end{array}$ \\
\hline Pelvic abscess & 3 & $\begin{array}{l}\text { Grade } \\
\text { III }\end{array}$ & Abscess drainage $(n=3)$ \\
\hline Wall abscess & 1 & $\begin{array}{l}\text { Grade } \\
\text { III }\end{array}$ & \\
\hline Septicemia & 3 & $\begin{array}{l}\text { Grade } \\
\text { IV }\end{array}$ & \\
\hline Hemorrhagic shock & 1 & $\begin{array}{l}\text { Grade } \\
\text { IV }\end{array}$ & \\
\hline $\begin{array}{l}\text { Severe respiratory } \\
\text { failure with } \\
\text { intubation }\end{array}$ & 2 & $\begin{array}{l}\text { Grade } \\
\text { IV }\end{array}$ & \\
\hline Death & 1 & $\begin{array}{l}\text { Grade } \\
\text { V }\end{array}$ & \\
\hline Late (36 patients) & 37 & & 37 \\
\hline $\begin{array}{l}\text { Ureteral } \\
\text { anastomosis } \\
\text { stenosis }\end{array}$ & 17 & & $\begin{array}{l}\text { Ureteral stenting or nephrostomy } \\
(n=16) / \text { reimplantation }(n=1)\end{array}$ \\
\hline Stoma hernia & 3 & & Bricker's revision $(n=3)$ \\
\hline Pyocystis & 3 & & Cystectomy $(n=3)$ \\
\hline $\begin{array}{l}\text { Obstructive } \\
\text { pyelonephritis }\end{array}$ & 7 & & $\begin{array}{l}\text { Ureteral stenting or nephrostomy } \\
(n=7)\end{array}$ \\
\hline $\begin{array}{l}\text { Obstructive renal } \\
\text { failure }\end{array}$ & 2 & & $\begin{array}{l}\text { Ureteral stenting or nephrostomy } \\
(n=2)\end{array}$ \\
\hline Lithiasis & 2 & & $\begin{array}{l}\text { Nephrolitothomy }(n=1) / \\
\text { lithotripsy }(n=1)\end{array}$ \\
\hline Incisional hernia & 1 & & $\begin{array}{l}\text { Abdominal wall reparation }(n= \\
\text { 1) }\end{array}$ \\
\hline Major prolapse & 1 & & Hysterectomy $(n=1)$ \\
\hline Tumor recurrence & 1 & & Urethral tumorectomy $(n=1)$ \\
\hline
\end{tabular}

NCCUD was performed without cystectomy in the following indications: skin ulcers $(n=9)$ and patients' preferences patterns of voiding $(n=6)$. A concomitant procedure was performed in 15 cases (mainly colostomy, sacrocolpopexy, and hysterectomy). The median length of stay was 20 days (IQR 17-25). A total of 67 early postoperative complications occurred in 44 patients: 30 Clavien

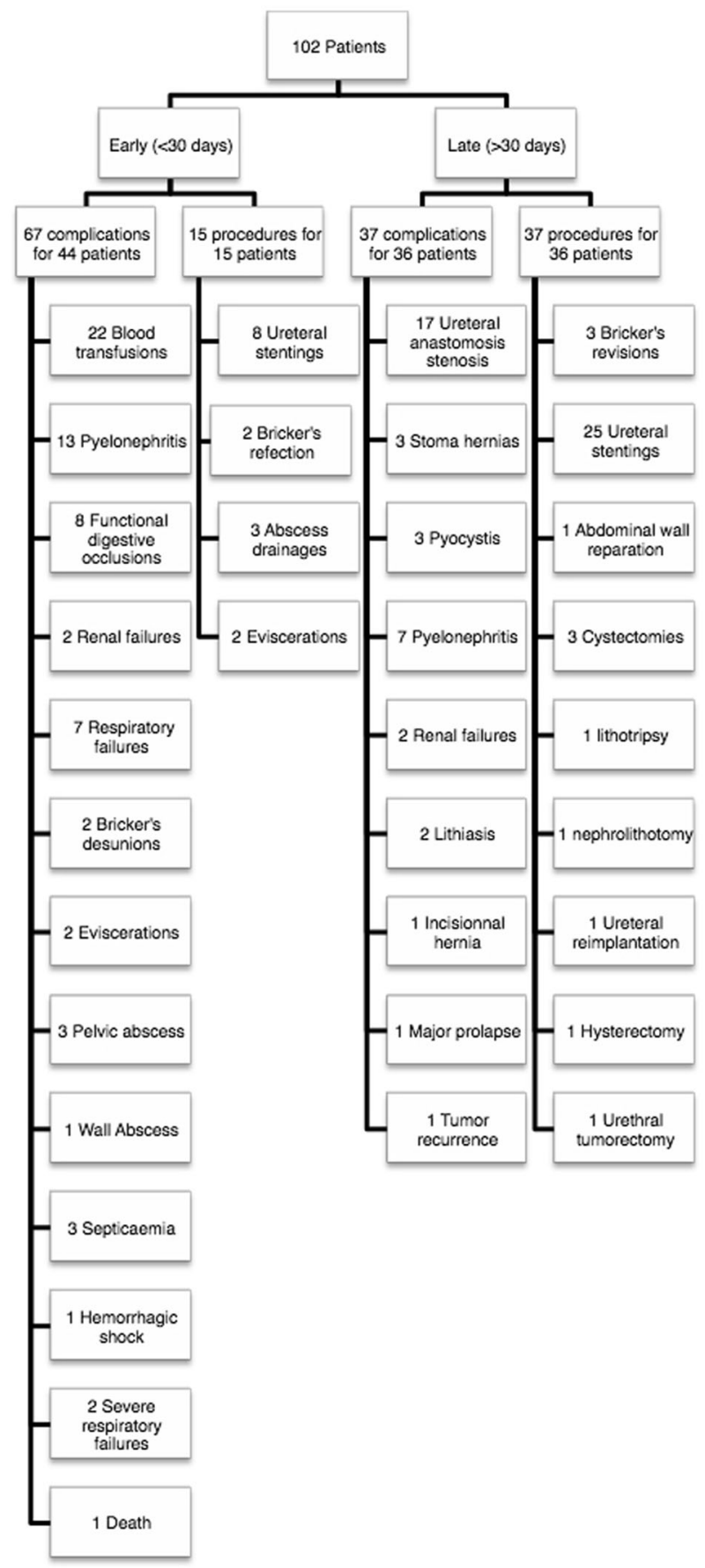

Fig. 1 Flow chart of the complications and the procedures (early and late)

I-II grades, 30 Clavien III, 6 Clavien IV, and 1 Clavien V (Table 3 and Fig. 1). The perioperative rate was $43 \%$ (44/ 102 patients). One death occurred at day 15 after surgery due to severe hepatic failure in a patient with cirrhosis. The early reoperation rate was $15 \%$ (15 procedures).

Among the four patients who had had a preoperative hydronephrosis, two showed either a decrease or resolution 
of dilatation. Eight patients had renal failure with a creatinine clearance below $60 \mathrm{~mL} / \mathrm{min}$. In only one patient was postoperative clearance raised above $60 \mathrm{~m} / \mathrm{min}$. Among those who did not have renal insufficiency, 12 had decreased their creatinine clearance below $60 \mathrm{~mL} / \mathrm{min}$ during the follow-up.

All the patients who underwent the NCCUD for perineal skin ulcers or urethrocutaneous fistula were dry after surgery, supporting the healing process.

\section{Long-term complications and outcomes}

A total of 37 late complications occurring in 36 (35\%) patients was reported during the follow-up, with a mean time of onset of 20 months, ranging from 2 to 117 months after initial surgery (Table 3 and Fig. 1). An additional surgical procedure within the median delay of 6 months (IQR 2-25.5) was performed in 37 cases. Seven deaths were reported but none was directly linked to the NCCUD or urological problems; there were three deaths by heart failure, two by respiratory failure, and two due to oncological issues.

Median postoperative creatinine clearance was $81 \mathrm{~mL} /$ min (IQR 54-100); there were no statistically significant differences compared to the preoperative clearance. Autonomy (data available for 56 participants) was reached in 49 patients (88\%) and the correct fitting of the stoma (data available for 60 participants) was achieved in 49 $(82 \%)$. Autonomy related to urinary function was significantly improved after NCCUD (95\% confidence inter$\mathrm{val}=72-92 \%)$. Ureteral stent changes had to be repeated every 3 months in nine (9\%) patients due to ureteral anastomosis stenosis. In the long term, autonomy and correct fitting of the stoma were still achieved.

\section{Discussion}

NCCUD using an ileal conduit has been a routine surgery in our department for the management of neurogenic bladder after failure of conservative therapies [13]. To the best of our knowledge, we present the largest series of NCCUD in patients with SCI.

In case of failure of conservative therapy, surgical diversion can be performed. Continent urinary diversions are performed if individuals can proceed to ISC and if they are considered fit for such a high-risk surgery. Moreover, the indication also depends on patients' preferences.

The early complication rate was quite high with a rate of $43 \%$, although most complications were minor in nature, that is, Clavien's grade of I or II. Furthermore, the early reoperation rate was $15 \%$. There was 1 death out of 102 patients, with an early mortality rate of $<1 \%$.
The late reoperation rate of $35 \%$ and the main late complication was ureteral anastomosis stenosis. There was only one case of reimplantation and $9 \%$ of patients had to remain with iterative ureteral stent change.

We found similar results in the literature regarding early and late complications [4].

Complications rates were higher and length of stay was longer in our series than what we could find in the literature in other indications. We can explain this by the fact that patients with SCI patients had more digestive and respiratory difficulties, which artificially increase the complications rate and the length of stay [14].

Follow-up is shorter than expected because some patients were followed in other centers and were only included for the surgical procedure.

Moreover, we reported our experience of open surgery, but in certain cases, laparoscopic procedures can also be performed in patients with SCI and produce interesting results [15].

This procedure preserved renal function by achieving a low-pressure drainage system. However, if patients have obstructive renal failure with renal cavity dilatation or even renal atrophy, it is surely too late to correct the renal function, as it should have been indicated earlier. That is why we did not have a significant improvement in term of renal function. Our study also shows a trend in the management of these patients with SCI with a higher volume of procedures from the past ten years, compared to the late 1990s. The impact of better long-term follow-up likely is part of the reason why this procedure was more frequently indicated. Aging individuals with SCI may also explain this new trend. We think that in many cases, NCCUD should be proposed as soon as a perfect control of bladder management cannot be obtained by ISC. In many cases, it is the surgery we proposed in elderly patients to offer a better quality of life. We also found a high rate of women in our study. It could be explained by the nature of the surgery which is more common and easier in women, with sometimes associated surgery, such as hysterectomy.

Another interesting finding of our study is the high proportion of cystectomy associated with the urinary diversion: 87 cases $(85 \%)$. In the early 2000 s, ChartierKastler et al. [13] reported a rate of $37 \%$ for concomitant cystectomies with a high rate of pyocystis $(58 \%)$ in a retrospective series of 33 patients. We report only three cases of pyocystis treated in all cases by a complementary cystectomy. Moreover, a retained bladder exposes the patient to the risk of others complications such as bladder cancer, pain, and hematuria [16]. We report two cases of epidermoid carcinoma. A retained bladder can also alter the general control of the disease [4].

It is also known that NCCUD improves the quality of life of patients with neurogenic bladder. In a prospective study, 
Guillotreau et al. [17] described an improvement of urinary quality of life, without any negative impact on the general quality of life in 48 neurological patients ( 38 multiple sclerosis, 7 SCI, and 3 unspecified) undergoing an ileal conduit. Other recent studies report an improvement of the quality of life of patients undergoing urinary diversion. Parek et al. [18] prospectively evaluated the health related quality of life in the pediatric population with spina bifida. This improvement could be explained by the better surgical care and appropriate stoma care that has been provided in the past years, as some authors have previously reported a bad social and emotional impact of the procedure, such as Nordström and Nyman [19] did for 66 patients. In our study, all patients who had perineal skin ulcers were dry after the procedure and the correct fitting of the stoma was obtained in $82 \%$. This high rate may be explained by the preoperative placement of the stoma $48 \mathrm{~h}$ prior to the surgery.

One limitation of our study is the lack of evaluation of quality of life. We evaluated the autonomy of the patient and the correct fitting of the stoma. It would have been interesting to measure the urinary or the general quality of life using specific questionnaires, given that the autonomy rate was higher and statistically significantly better after surgery.

Moreover, only 74 patients completed a follow-up of at least 1 year. Physicians from other centers can sometimes supervise the follow-up, while the surgery has to be performed in an expert center where adapted care can be provided. Moreover, patients feel cured once they have the NCCUD done, despite the real need to have serious followup of the ileal conduit and to prevent complications related to the stoma.

Despite a rate of $43 \%$ of early complications and a rate of $35 \%$ of late reoperations, NCCUD should be offered to patients with SCI after failure of conservative therapies or as a salvage therapy in order to preserve upper urinary tract function and achieve autonomy. However, this surgery should probably be considered earlier, taking into consideration patients' neurological condition and expectations. Such patients are often referred to expert centers that can perform the procedure and provide adapted perioperative and postoperative care. The inconstant long-term results and the expected complications warrant permanent follow-up by a multidisciplinary team.

Even if the indication is not immediately life threatening, it is crucial for the patients to have a low pressure upper urinary tract system. Moreover, if the pattern of voiding does not allow complete voiding of the bladder, this will lead to a high rate of lithiasis and/or urinary tract infection which can cause severe complications. The main goals of management of neurogenic bladder disorder are protection of the upper tracts, with low-pressure continent drainage where possible. Still, we must accept that continence is not a realistic option for some individuals. In such cases, noncontinent diversion techniques need to be considered. The technique chosen will depend on a myriad of factors, not least of which are the preferences of the individuals with SCI or their caregivers.

Acknowledgements We thank Eleonora Spanudakis for her review of the manuscript.

\section{Compliance with ethical standards}

Conflict of interest The authors declare that they have no conflict of interest.

\section{References}

1. Lapides J, Diokno AC, Silber SJ, Lowe BS. Clean, intermittent self-catheterization in the treatment of urinary tract disease. J Urol. 1972;107:458-61.

2. Weld KJ, Dmochowski RR. Effect of bladder management on urological complications in spinal cord injured patients. J Urol. 2000;163:768-72.

3. Blok BF, Pannek J, Castro-Diaz D, del Popolo G, Groen J, Gross $\mathrm{T}$ et al. Guidelines on neuro-urology.Eur Urol. 2015;17-23.

4. Bart S, Game X, Mozer P, Ruffion A, Chartier-Kastler E. Noncontinent cutaneous urinary diversion in neurourology. Prog En Urol J Assoc Fr Urol Société Fr Urol. 2007;17:552-8.

5. Legrand G, Rouprêt M, Comperat E, Even-Schneider A, Denys P, Chartier-Kastler E. Functional outcomes after management of endstage neurological bladder dysfunction with ileal conduit in a multiple sclerosis population: a monocentric experience. Urology. 2011;78:937-41.

6. Bricker EM. Bladder substitution after pelvic evisceration. Surg Clin N Am. 1950;30:1511-21.

7. Cordonnier JJ. Ileocystostomy for neurogenic bladder. J Urol. 1957;78:605-10.

8. Bennett CJ, Young MN, Adkins RH, Diaz F. Comparison of bladder management complication outcomes in female spinal cord injury patients. J Urol. 1995;153:1458-60.

9. Malone PR, Stanton SL, Riddle PR. Urinary diversion for incontinence- $\mathrm{a}$ beneficial procedure. Ann R Coll Surg Engl. 1985;67:349-52.

10. Wallace DM. Ureteric diversion using a conduit: a simplified technique. Br J Urol. 1966;38:522-7.

11. Dindo D, Demartines N, Clavien P-A. Classification of surgical complications: a new proposal with evaluation in a cohort of 6336 patients and results of a survey. Ann Surg. 2004;240:205-13.

12. Martin RCG, Brennan MF, Jaques DP. Quality of complication reporting in the surgical literature. Ann Surg. 2002;235:803-13.

13. Chartier-Kastler EJ, Mozer P, Denys P, Bitker M-O, Haertig A, Richard F. Neurogenic bladder management and cutaneous noncontinent ileal conduit. Spinal Cord. 2002;40:443-8.

14. Mossanen M, Krasnow RE, Lipsitz SR, Preston MA, Kibel AS, $\mathrm{Ha} \mathrm{A}$ et al. Associations of specific postoperative complications with costs after radical cystectomy. BJU Int. 2018;121:428-36.

15. Guillotreau J, Gamé X, Castel-Lacanal E, Mallet R, De Boissezon $\mathrm{X}$, Malavaud B, et al. Laparoscopic cystectomy and transileal ureterostomy for neurogenic vesicosphincteric disorders. Evaluation of morbidity. Prog En Urol J Assoc Fr Urol Société Fr Urol. 2007;2:208-12. 
16. Eigner EB, Freiha FS. The fate of the remaining bladder following supravesical diversion. J Urol. 1990;144:31-3.

17. Guillotreau J, Castel-Lacanal E, Roumiguié M, Bordier B, Doumerc N, De Boissezon X, et al. Prospective study of the impact on quality of life of cystectomy with ileal conduit urinary diversion for neurogenic bladder dysfunction. Neurourol Urodyn. 2011;30:1503-6.

18. Parekh AD, Trusler LA, Pietsch JB, Byrne DW, DeMarco RT, Pope JC, et al. Prospective, longitudinal evaluation of health related quality of life in the pediatric spina bifida population undergoing reconstructive urological surgery. J Urol. 2006;176:1878-82.

19. Nordström GM, Nyman CR. Living with a urostomy. A follow up with special regard to the peristomal-skin complications, psychosocial and sexual life. Scand J Urol Nephrol Suppl. 1991;138:247-51. 